\title{
Critical Participatory Looping: An Agencing Process for Mass Customization in Language Education
}

\author{
Tim Murphey (Chiba) \& Joseph Falout (Tokyo)
}

\begin{abstract}
Critical Participatory Looping (CPL) (cf. Falout and Murphey 2010; Murphey and Falout 2010) involves returning processed data from surveys or assignments back to students for further reflection and analysis in small groups. CPL affords dialogical interaction among class members (including the teacher), which can encourage them all as agents developing their own self-determination through action-otherwise known as agencing (cf. Murphey 2010, Nelson and Murphey, 2011). In this paper we first describe the kinds of customization that invite agency, then for CPL provide three examples of teaching and researching with it, theorize on its processes and potential, and discuss its correlates with other domains and mass customization.
\end{abstract}

\section{$1 \quad$ Agency in Customization}

In mass customization, Thomke and Von Hippel (2011: 120-121) suggest "using tool-kits that enable customers to become innovators." They contend that the "goal is to provide customers with enough creative freedom to design innovative custom products that will truly satisfy their needs." For education, this idea might translate as student-centered teaching that can provide students with a set of strategies and procedures so they can produce their customized learning - made mostly by them and for them, sometimes referred to as independent learning or autonomy, and what others might call manifested agency.

Thomke and Von Hippel (ibid.) further suggest that, "Outsourcing a portion of the innovation task to customers can be an effective approach for speeding up the development of products better suited to customer needs." In teaching, this outsourcing can at first take the form of asking for feedback from students to speed up the development of teaching, materials, and activities better suited to student needs. Then later, with the development of trust and independence, students can be asked to design their own projects and procedures.

Thomke and Von Hippel (ibid.) conclude that, "Exactly where the value will be generated and how it might best be captured are multimillion-dollar questions facing companies competing in industries that are being transformed by customers as innovators." Similarly in education, exactly where the valuable transformations will occur and how they might be used are questions facing teachers in cutting edge classrooms that are being transformed by students as innovators, collaborators, and developers. The ways of getting the feedback can be generalized, but appropriate feedback customized for each teacher's specific situation can be initiated by their students, who are the most aware of what is happening in their teacher's classrooms and in the timeframes as they happen. Adapting collaboratively with students, for and according to their individual developmental stages, and within the moment of dynamic and evolving teaching contexts, can be described as just in time teaching (JITT: Edwards, Mehring, and Murphey 2006). We could also call such adaptation a bottom up emergence of innovation 
(Johnson 2001), which teachers may not have much control over, but with which they can cultivate the environments that make collaborative educational transformation more likely.

Self-determination theory (cf. Deci and Ryan 2002) holds that people can become motivated when their three basic psychological needs are met: competence, relatedness, and autonomy. Customization in language education motivates when it allows increases in skill development (competence), bonding with collaborators (relatedness), and a greater sense of control over processes and products (autonomy). Customizing to students' levels of competence in interactive groups can provide both a sense of relatedness to co-members and a sense of autonomy that they can act meaningfully in their world. Thus customizing can form an agencing process activating goal-directed behavior, effort, persistence, flow, and other generally positive emotions associated with self-determination.

However, a problem arises when customization is attempted for the masses - the three basic psychological needs may not always be met. This leads us to propose three types of customization which might be described as false-customization, shallow-customization, and deepcustomization depending on the degrees of agency involving the user.

False-customization appears to offer control, but the overall structure has been predetermined. It is false in that aspects pretend to be customized when really they are regimented and programmed into the system, as when an automated reply uses your name in an automatic letter. For another example, the "choose your own adventure" stories seem to bring an element of customization to readers because they make choices as if they were the living protagonist, reading narratives in second-person and directing the plotline by turning to the pages indicated. But in the end the reader is invited to be manipulated by the book more than vice versa, with the adventure determined more by the reader's compliance than autonomous action. All possible plotlines are prewritten and the reader holds no agency in the textual production of the story.

Shallow-customization invites a limited amount of user agency and offers a determinable number of outcomes. For example, the burger restaurant where customers can choose the burger size, the bun flavor, and the toppings and relishes - user choice is possible, but at some point there are limitations. According to Thomke and Von Hippel (2011: 120-121), "The classic example is the Dell computer: Consumers can buy a Dell computer by picking the major components they want (the size of the hard drive, the kind of monitor, the number and types of memory modules, and so on) from a menu on a Dell Web site. The company assembles and delivers the custom products in days." But it is shallow because "The company's customers have only a limited number of standard components and combinations to choose from, leaving them little room for creativity or real innovation" (ibid.).

Deep-customization invites a maximum amount of user agency and offers endless possible outcomes. For example, a paint company may have a determinate number of paint colors, templates, and brushes, but the user has manifold choices at ready disposal - indeterminate combinations of where and how to paint a room, mix paint colors, apply the paint through various techniques, express oneself through ways such as murals and decorative details.

False-customization for education might be illustrated by a teacher asking students to write their individual opinions on the topics they are going to study that term. The teacher collects and reads the opinions, and even quotes ideas that match predetermined lesson plans in lectures and handouts, but regardless of what students said, goes on with the predetermined lessons and syllabus. A teacher doing shallow-customization might read the opinions and then construct a reading syllabus around the most desired chapters. Deep-customization might occur when the teacher actually creates tables of topics students said they liked, looked forward to, or did not; or prints up different extracts from the students' comments to redistribute to students to talk further about in the next class, then discusses possible changes in the syllabus 
based upon students' preferences, maybe mixed with teacher input, and creating a reading list. This last example is a form of CPL and may indeed restructure syllabi and curricula when teachers are more open to student participation in their own education.

Mass customization in language education can invite students' and teacher's agency and their possibilities of learning. CPL invites deep-customization of meaningful understandings through dialogic interactions in classes about participants' own work and data, promoting education through their own agentive and autonomous actions. The process starts when teachers provide a format for collecting data, e.g. surveying students about their language learning or asking them to reflect on their experiences and write about them (see case studies below). Often the data can be compiled into tables, charts, etc., and returned to the students for further reflection and analysis. The students then discuss in small groups how these data pertain to their language learning, and offer their own interpretations back to the teacher, as well as suggestions for changes in education.

\section{$2 \quad$ Using CPL in Three Case Studies}

Transparency about the process is key to conducting critical participatory looping (CPL). We tell our students that their contributions are for informing themselves, their peers and teachers, and the wider educational system through our (their teachers') conference presentations and journal publications. Students themselves even begin to broadcast their ideas beyond the classroom, taking their agencing to new levels with CPL, as will be explained in the third case study. Without this transparency, the CPL process might appear as just another classroom activity. With this transparency comes a sense of agency, a heightened participation because their voices matter, an awareness that their participation might lead to better education for themselves and others, and an enthusiasm and commitment to help make that change possible.

\subsection{Case Study 1: Motivation and Demotivation}

Using an open-ended questionnaire, we asked 440 students from four universities to reflect back on their junior high school (JHS) and high school (HS) experiences to find what motivated and demotivated them (cf. Falout et al. 2008; Murphey et al. 2009). We coded the data, ranking the top positive and negative experiences, and gave these tables back to the students, who subsequently found something surprising to them. One of the top positive experiences was grammar, yet it also ranked near the top in the negative category. Students believed this was not an accurate representation of the data, and furthermore the positive ranking could not be a probable or accurate finding, for they believed most of their peers flatly disliked grammar study. A large number of such comments dominated the type of responses in this part of the loop. This made us go back to the original data set to disambiguate the findings.

In our reanalysis we found that a large proportion of the students indeed disliked grammar to a great extent, particularly when it had been presented mono-methodically through the grammar-translation method, shown to be a leading demotivator in this educational context (cf. Falout et al. 2009). Also some had liked grammar in HS, but only in the conditional sense that they found it effective for helping them pass the college entrance exams. Very few students had any intrinsic interest in grammar, even for the students majoring in English. In our first layer analysis we represented students' experiences and beliefs in tables that had conflated what was useful and enjoyable into one category, which was not valid, and our students' feedback made us aware of it. Through the second layer of analysis we were able to provide a table with a more representative and detailed account of students' relationship toward grammar study, and this improved everyone's understandings and our research. We couldn't have achieved these mutual understandings without inviting our students to enact their agency. 


\subsection{Case Study 2: Remotivation and Maintaining Motivation}

Using an open-ended questionnaire, we asked 285 students from four universities to reflect back upon what demotivated and remotivated them, and what strategies they use to maintain motivation (cf. Carpenter et al. 2009). The last question asked what they thought about this questionnaire. Forty percent replied that this was the first time they had reflected upon their experiences learning English as a foreign language (EFL), and that this reflection helped them to positively re-conceptualize their purposes and ways of learning. Also, knowing their peers were answering the same questions, they wanted to learn how the others maintained motivation and requested this information from us. Therefore we made a table of the top twenty strategies to maintain motivation and looped it back to them, asking them to separately mark which strategies they had tried, and which they wanted to try. The last question asked what they thought about this research. Analyzing this second loop, we found that through their participation, our students felt competence, relatedness, and autonomy.

By reading this table of motivational strategies, students felt that their study styles were validated when they found others studying the same way, leading to a sense of competence in their learning behaviors. For example, some realized that listening to music for enjoyment is a serious way to raise motivation and pursue L2 acquisition. Students felt relatedness by sharing information with each other not just in class, but with students from other classrooms and universities. The science majors were interested in knowing that English majors had their strategies mixed into the data, and English majors were interested in learning that other students had struggled to maintain motivation learning English. Students felt autonomy by teaching and learning from both their in-class friends and other-class counterparts, learning to learn through interacting with near peer role models (cf. Murphey and Arao 2001). Finally, asking their teachers to show them further research results is an agentive act, and our following their investigatory initiatives by returning the results, and asking for further input from the students, formed iterative and interdependent loops of competence, relatedness, and autonomy among the 290 students and the teachers. Together all of us were agencing our learning, teaching, and researching strategies.

\subsection{Case Study 3: Histories and Futures}

Another way of agencing though CPL can start with class activities. For the first semester in 2009, Murphey (2012) asked students to write their language learning histories (LLHs), describing their early English learning experiences up through the present, including the ups and downs in their motivations, struggles and successes, and why they managed the way they did. He collected these LLHs, published them in booklets, and distributed them in class, so students could read about their peers' goals and strategies for learning EFL.

Then in the second semester, in small groups, they re-read the LLHs and discussed what were the common motivational and demotivational factors, identified potential problems in the educational system, and proposed solutions for students, teachers, and the Japanese Ministry of Education, Culture, Sports, Science and Technology (MEXT). The reports became class publications, again in booklets, and were sent to MEXT. They did this in the hope that their proposals might help improve the way EFL is taught in the future through giving suggestions to students, teachers, and policymakers.

Finally, a summary of the reports-booklets was adapted for a 3-minute video clip, performed by some of these same students, and uploaded to YouTube on January 20, 2010, and after two and a half years (at the time of writing) it has about 416,000 visits. Many viewers also wrote very positive messages in the comment section, expressing empathy and support. The students could read these comments and feel even more competency as shapers of ideas around the world, relating to so many people expressing similar opinions internationally, and feeling 
some pride and power that they were able to communicate in English about serious matters. Two students commented on the video during the first year:

I was very surprised at a lot of messages over the world. I was happy that most of them knew our REAL VOICE and agreed with us. And I hope this video will be a good opportunity to rethink about the system or guideline of English teaching. I want JHS/HS students to watch it and hope they feel something about their study. (Student 1)

Watching Real Voice video, I'm very glad and honored to have joined this project. If I were not a student in this class, I couldn't have done such wonderful and useful activity for students who will study English in the future. (Student 2)

When students write their LLHs and teachers read them, teachers become better equipped to customize their classes in ways that more closely cater to their students' needs and desires. Thus, the activity of LLHs can itself be a candidate for mass customization in language education. Going a step further to return compiled sets of LLHs back to students to analyze in groups is then CPL. LLHs can also be done with the masses, but each layer of understanding begins as local responses, as any version of CPL. Making a video for the masses about local concerns creates room for these concerns to become a topic worthy of international debate. Looping across media and national borders shows the agencing processes of teachers and their students.

\section{The Process of CPL}

With CPL we are checking with our students about their beliefs, reflections, and motivations in learning. The process is similar to member checking, common in ethnographic research (cf. Lincoln and Guba 1985), when researchers follow up interviews by checking and confirming with the participants what they meant (Figure 1). Although this method is pragmatic for ethnographers doing data interpretation and validation when interviewing individuals in the field, it may be overly labor intensive for busy teachers. Instead, with CPL we invite small groups of students to collaboratively do the "checking" and interpretation of data, making a loop of meaningful feedback (Figure 2).

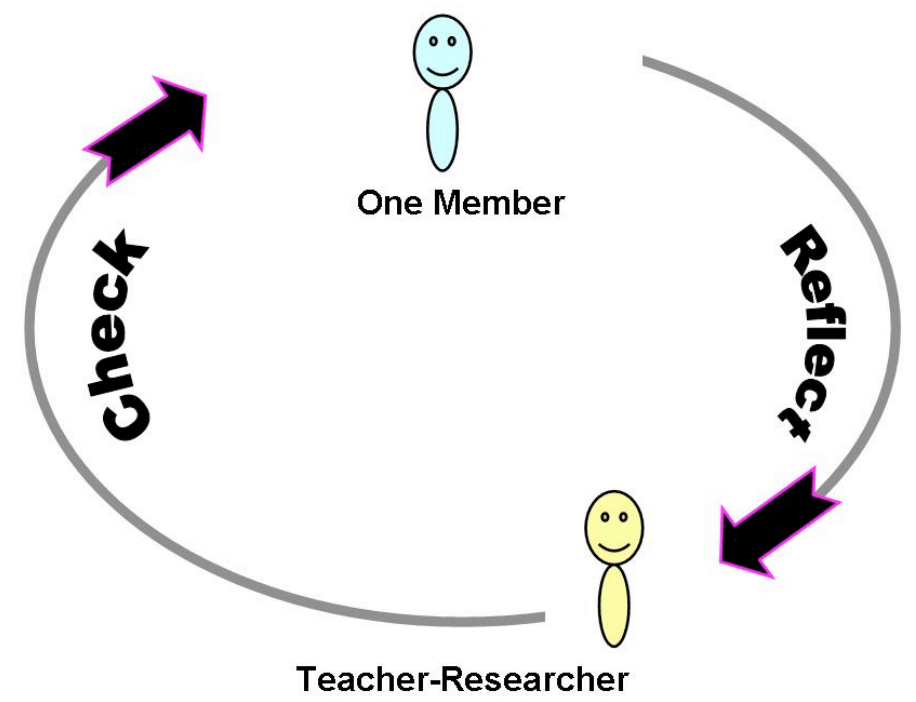

Figure 1: Member checking in ethnography 


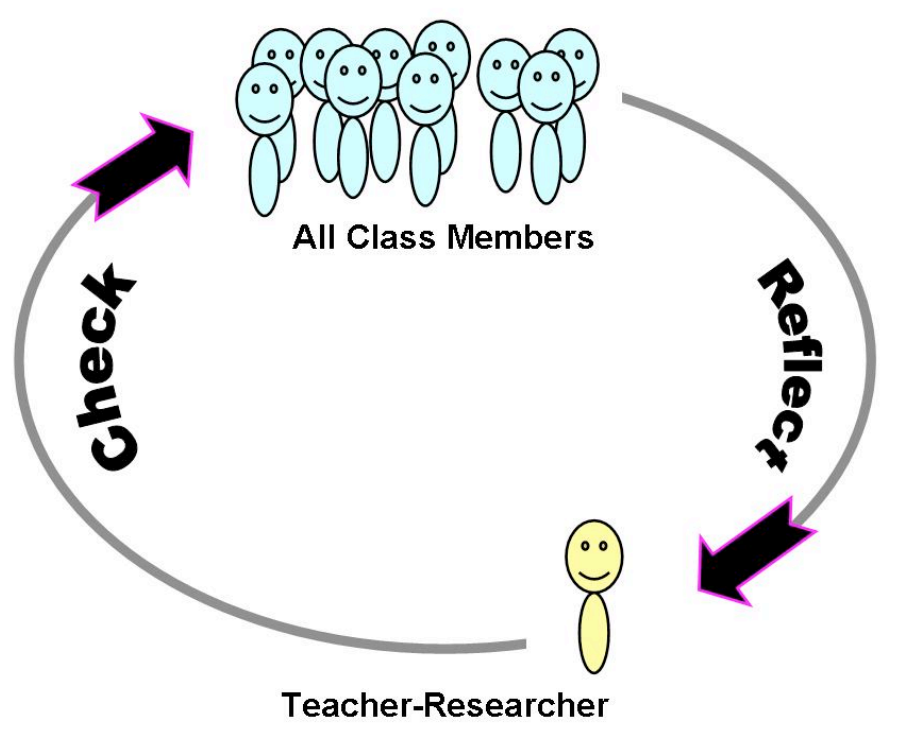

Figure 2: Member checking with whole classes

CPL is also similar to action research (cf. Lewin 1946), which is conducted in classrooms and other communities with a concerned group of people who focus on something in their environment to develop or improve. In action research they typically plan, act, observe reactions, and reflect on results before planning again for a whole new cycle. However, when teachers forget to include their students in the reflection stage, they isolate themselves with their own interpretations and position students as agentless objects (Figure 3). When keeping students in the loop, we create a more cooperative community that can greatly benefit from each others' perspectives and insights as the above three case studies show (Figure 4).

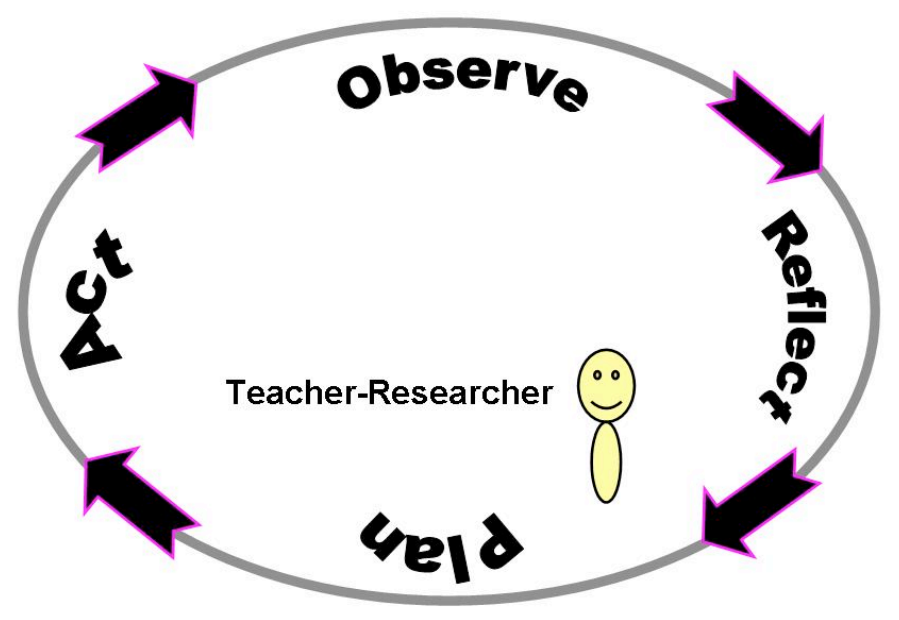

Figure 3: Solitary action research 


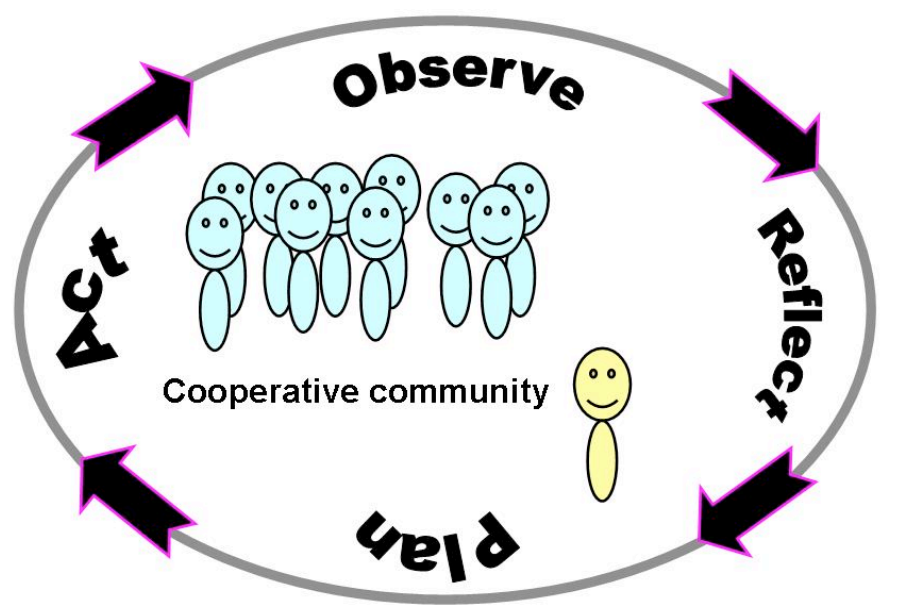

Figure 4: Action research with a CPL community

CPL becomes an agencing process for students when they can see their involvement having influence over their internal and external learning environments, including their own and their teacher's beliefs and practices, developed through reflection and action. Somewhat mirroring action research, CPL involves Dewey's (1910) four stages of reflective thinking - experience, description, analysis, intelligent action - simultaneously and with as many loops as the agents desire (Figure 5). We do not pretend that the process is easy, for it requires teachers to learn and adjust (cf. Murphey in press) to their students' input, and it requires students to build critical perspectives and convey them to their teachers. It takes both courage and practice for all to shift from traditional roles into blending them (Figure 6).

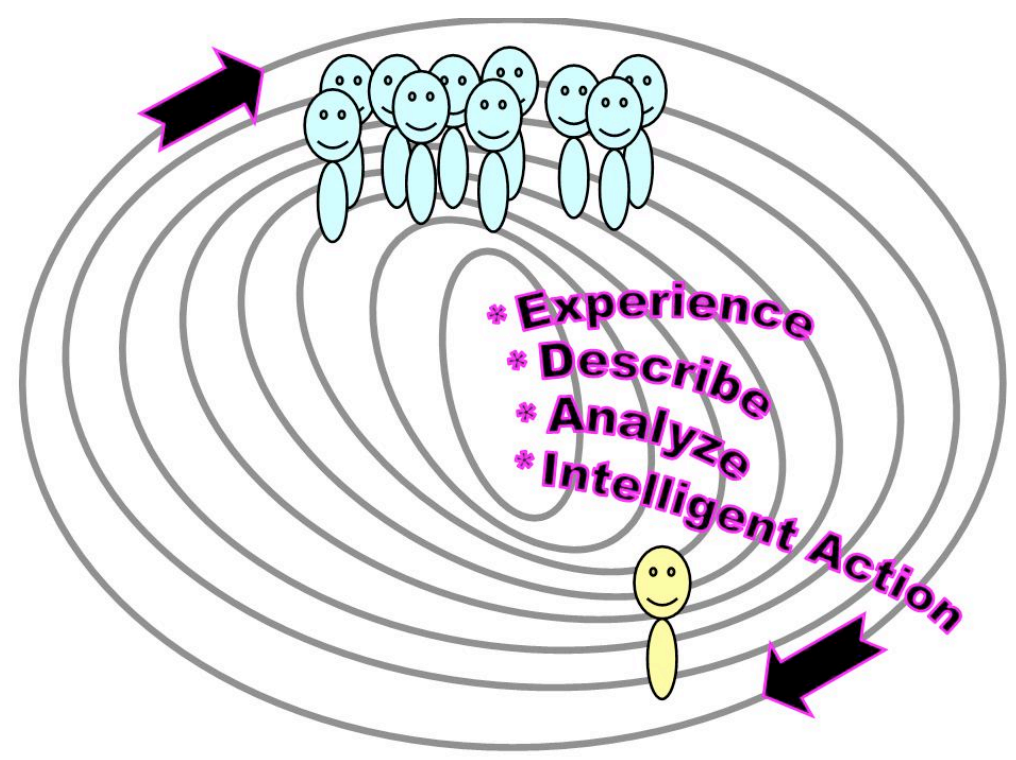

Figure 5: Critical Participatory Looping 

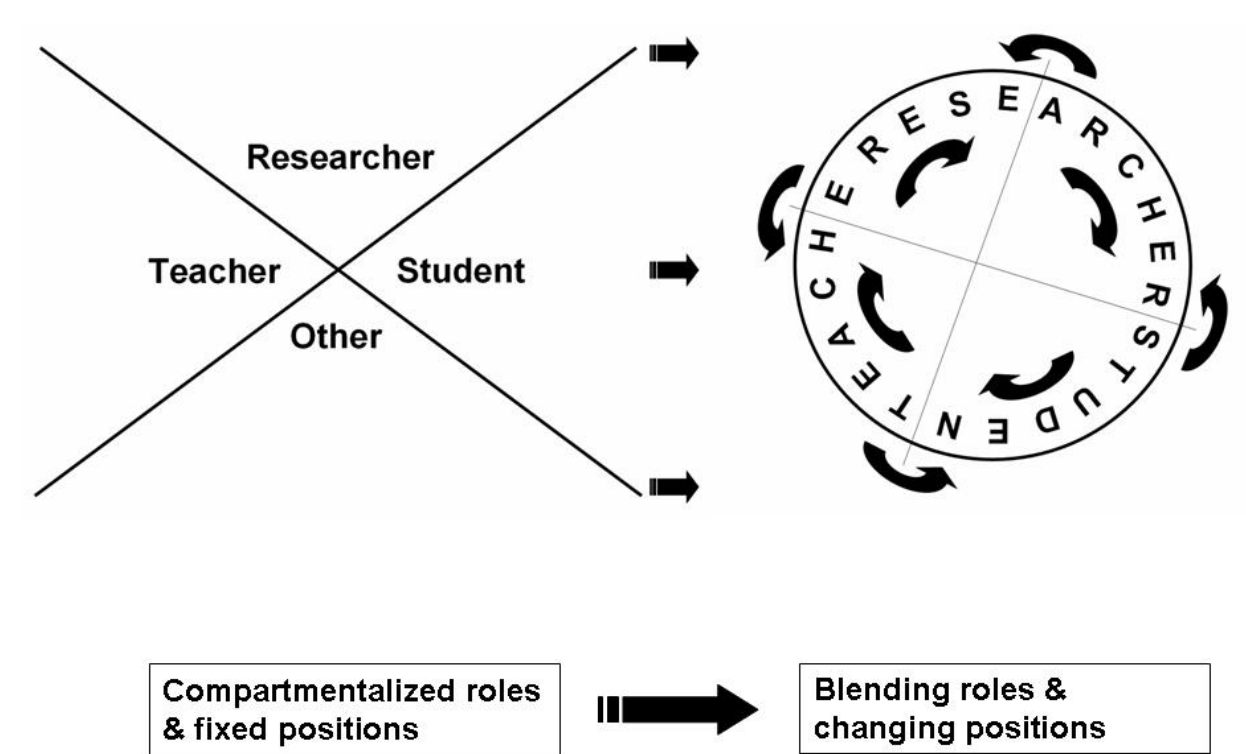

Blending roles \&

changing positions

Figure 6: Transforming roles and positions

The CPL process also allows at least three possible sociocultural levels of customization. At the individual level, students can learn how to learn through personal reflection and shared observations with their peers. These interactions bring individual autonomy through greater control about the purposes and pathways of their own learning. Such socially mediated agencing emerges from and contributes to positive group dynamics, what we call present communities of imagining (Murphey et al. 2012). At the classroom level, teachers are learning deeper about their students' experiences and affective needs. Teachers can better meet these needs by adjusting and customizing lesson plans and syllabi, and their day-to-day interactions with students, based on the feedback they give. At the educational systems level, policymakers reading research results, letters, or petitions generated through CPL can gain a deeper understanding of the variety of student and teacher needs, and attempt to meet these by creating or adjusting recommended curricula, and educational incentives and policies. Hopefully they can recommend structures that allow individual schools, teachers, and classes to customize things for themselves, inviting their agency to fit their particular needs, and promote ways of increasing their knowledge and skills.

\section{Discussion: Customizing Language Education}

Regarding the practice of teaching languages, Allwright and Hanks (2009: 1) suggest that we "put learners fully at centre-stage, alongside teachers, as key developing practitioners in their own right." CPL attempts to do this through inviting students into research about their own learning and themselves, suggesting that they can and should become more instrumental in creating their own education, inviting them to become more agentive in controlling how and what they learn.

It is important to note that CPL itself is massively customizable locally. We stress that it doesn't have to be used for motivation research - it might prove an alternative way for other forms of research and even testing (cf. Murphey 1989, 1995). We believe CPL could be used to creatively investigate various aspects of language learning, such as assessing grammatical and vocabulary knowledge. Wouldn't it be great to create a wisdom-of-the-crowds type of mass investigation with students all pitching in together to find out what foreign language knowledge and skills they have and don't have and think essential? 
Numerous studies show that large, diverse, and knowledgeable groups of people working together on issues and problems are much more likely to come up with effective answers, plans, activities, moves, and guesses than any small group of experts - especially when the small group is overly homogeneous (cf. Surowiecki 2004). The process works through decentralizing and allowing local control and knowledge building by aggregating information and opinions that are shared between the larger and local communities.

Edward Demming, advocate of listening to workers' voices, used this principle in quality control for mass production, assisting Japan's resurrection after World War II. In the industries that adopted Demming's proposals, the average Japanese worker provided management with 28 suggestions a year, and $80 \%$ were acted on (Wall et al. 1992). The "workers" in education are not only teachers but also students and they need to be heard if we want them to take their work (i. e. their study) seriously and see it as meaningful for their lives. While industry seems to have figured this out in Japan, education in Japan and many parts of the world has not. And although education's modeling of industry certainly can go astray, there are some ideas originating in business from which we might benefit.

In many modern companies, "Employees drive performance by collaborating with peers across organizational boundaries, creating what we call a 'wiki workplace'" (Tapscott and Williams 2006: 1). Moreover, many customers become prosumers by co-producing goods and services rather than simply consuming the end product. A parallel phenomenon in education would mean staff and teachers collaborating more broadly across departments and students being not just consumers, but producers (prosumers) of each others' learning. Prosumers are already active in places like MySpace and Wikipedia. Tapscott and Williams call this a participation revolution in which peering - inviting others to be your peers and participate in projects - allows us to tap into the wisdom of a large group of people and aggregate their knowledge and skills.

The psychology and behavioral economics writer Dan Ariely (2010) describes what he calls the Ikea effect in which we are more proud of and value more the things that we have a hand in creating, whether they be cakes, furniture, or education. This agency to at least partially construct something in our own way is very similar to mass customization but would generally not be very common without do-it-yourself types of stores. Thus, this opportunity for customization is most often created by others for us, and often is a marketing tool. Nevertheless, it still depends on us having the agency to actually choose to act upon it. We see the do-ityourself home centers as scaffolding the agency of consumers and turning them into prosumers who produce and consume and feel more agentive. We have seen in our own classes that students can become prosumers of their learning. So the question is how can teachers scaffold opportunities of agency-in-action for students to become producers of their own learning? As with the Ikea effect, students can learn more and value their education more when they have more say in organizing content and processes. CPL seems to be one process that allows this to happen deeply.

From her research on mass customization in schools, Waslander (2007) presents the basic economic law that diversity (customization), in terms of products and services, adds costs. She further explores the diversity-efficiency dilemma when facing customers, clients, or students - to be maximally efficient, we want to have a minimal number of products, services, and routines. However, to match a greater number of people, we want to have more options, which can seem less efficient and more costly to maintain. Waslander (2007: 378) also insightfully draws a line between products and services, stating about the latter for education, "what students value most is 'to be(come) somebody' and be known by staff." We think that the CPL process allows students to feel like they are meaningfully contributing to the structure of the class and that each one feels "I am somebody" who potentially has an impact by 
becoming known by peers, teachers, administrators, and policymakers. By agentively inviting students to become prosumers of education, CPL affords deep customization.

\section{Conclusion}

Through our reflections above we are beginning to realize that acting agentively actually drives one's sense of agency. Even when not successful, the act of trying to improve things can make one feel as an active agent and a "somebody" performing meaningfully in the world. In customizing their own education, CPL helps students to accept trying. This spin on Michael Jordan's famous quote, "I can accept failure, but I cannot accept not trying," reveals a powerful process that creates persistence and willingness to take minor risks toward lofty goals, welcomes challenges and intriguing unanswerable questions, and invites involvement in experiences that help people become somebody they want to be, a striver. Our experience is that CPL can scaffold many students into engagement and acting agentively to change their worlds, to be self-determined and recognizable agents of action in both failure and success.

\section{References}

Allwright, Dick/Hanks, Judith (2009): The Developing Language Learner. Basingstoke, UK: Palgrave Macmillan.

Ariely, Dan (2010): The Upside of Irrationality: The Unexpected Benefits of Defying Logic at Work and at Home. New York: Harper Collins.

Carpenter, Chris/Falout, Joseph/Fukuda, Tetsuya/Trovela, Maria/Murphey, Tim (2009): "Helping students repack for remotivation and agency". In: Stoke, Alan (ed.) (2009): JALT2008 Conference Proceedings. JALT, Tokyo: 259-274.

Dewey, John (2010): How we think. Boston: D. C. Heath.

Edwards, Jennifer/Mehring, Jeff/Murphey, Tim (2006): "Exploring JiTT: Just-in-TimeTeaching". The Language Teacher 30/12: 9-13.

Falout, Joseph/Murphey, Tim (2010): "Loop it! Student participatory research". In: Stoke, Alan (ed.) (2010): JALT2009 Conference Proceedings. JALT, Tokyo: 370-380.

Falout, Joseph/Murphey, Tim/Elwood, James/Hood, Michael (2008): "Learner voices: Reflections on secondary education". In: Bradford Watts, Kim/Muller, Theron/Swanson, Malcolm (eds.) (2008): JALT2007 Conference Proceedings. JALT, Tokyo: 231-243.

Johnson, Steven (2001): Emergence: The Connected Lives of Ants, Brains, Cities, and Software. New York: Scribner.

Muphey, Tim/Falout, Joseph/Fukada, Yoshifumi/Fukuda, Tetsuya (2012): Group dynamics: Collaborative agency in present communities of imagination. Psychology for Language Learning: Insights from Research, Theory, and Practice. Basingstoke, UK: Palgrave Macmillan.

Murphey, Tim (1989): "Student-made tests". Modern English Teacher 17/1\&2: 28-29.

Murphey, Tim (1995): "Tests: Learning through Negotiated Interaction". TESOL Journal 4/2: $12-16$.

Murphey, Tim (2010): "Creating languaging agencing". The Language Teacher 34/4: 8-11.

Murphey, Tim (2012): "Creating Wow! With artifacts". PeerSpectives 8: 16-19.

Murphey, Tim (in press). Adapting ways for meaningful action: ZPDs and ZPAs. Meaningful Action: Earl Stevick's Influence on Language Teaching. Cambridge: Cambridge University Press.

Murphey, Tim/Falout, Joseph (2010): "Critical participatory looping: Dialogic member checking with whole classes". TESOL Quarterly 44/4: 811-821.

Murphey, Tim/Falout, Joseph/Elwood, James/Hood, Michael (2009): Inviting student voice. Accepting Alternative Voices in EFL Journal Articles. Busan, Korea: Asian EFL Journal Press: 211-235. 
Nelson, Terry/Murphey, Tim (2011): "Agencing and Belonging in the Collaborative Village: Case Studies from Two Asian Contexts". Anglistik 22/1: 81-100.

Real Voice: Suggestions for Changing English Education for Future Generations from 1st Year University Students. http://www.eltnews.com/columns/mash/MasterEngRepFresh 2010Complete.pdf [accessed July 24, 2012]

Surowiecki, James (2004): The Wisdom of Crowds. NY: Doubleday.

Tapscott, Don/Williams, Anthony (2006): Wikinomics: How Mass Collaboration Changes Everything. New York: Penguin.

The real voice of Japanese students. YouTube: http://www.youtube.com/watch?v= MwsZ0KiHhRg [accessed July 24, 2012].

Thomke, Stefan/Von Hippel, Eric (2011): "Customers as Innovators: A new way to create value". In: Johnson, Steven (ed.) (2011): The Innovator's Cookbook: Essentials for Inventing What is Next. New York, Riverhead: 101-121.

Wall, Bob/Solum, Robert/Sobol, Mark (1992): The Visionary Leader. Rockman, CA: Prima.

Waslander, Sietske (2007): "Mass customization in schools: Strategies Dutch secondary schools pursue to cope with the diversity-efficiency dilemma". Journal of Education Policy 22/4: 363-382. 